Article

\title{
Constitutive and Induced Expression of Total Phenol and Phenol Oxidases in Wheat Genotypes Ranging in Resistance/Susceptibility to the Root-Lesion Nematode Pratylenchus thornei
}

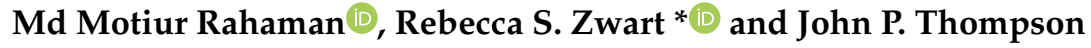 \\ Centre for Crop Health, University of Southern Queensland, Toowoomba, QLD 4350, Australia; \\ MdMotiur.Rahaman@usq.edu.au (M.M.R.); john.thompson@usq.edu.au (J.P.T.) \\ * Correspondence: rebecca.zwart@usq.edu.au; Tel.: +61-7-4631-1544
}

Received: 31 March 2020; Accepted: 8 April 2020; Published: 9 April 2020

check for updates

\begin{abstract}
Plant-derived phenolic compounds contribute to the defense against various pathogens, including root-lesion nematodes (Pratylenchus spp.). However, there are no reports on the role of phenolic compounds in wheat (Triticum aestivum) against Pratylenchus thornei. In this study, wheat genotypes ranging from resistant to very susceptible to $P$. thornei were used to investigate the level of total phenols and phenol oxidases, polyphenol oxidase (PPO), and peroxidase (POD) expressed in root tissues when grown in the presence and absence of $P$. thornei over time (2-8 weeks). Higher constitutive levels of total phenols were found in resistant synthetic hexaploid wheats CPI133872 (576 $\mu \mathrm{g}$ gallic acid equivalent (GAE)/g root) and CPI133859 (518 $\mu \mathrm{g} \mathrm{GAE} / \mathrm{g}$ root) at 8 weeks after sowing, compared with moderately resistant and susceptible genotypes (192 to $390 \mu \mathrm{g}$ GAE/g root). The activity of PPO was induced in resistant (CPI133872) and moderately resistant (GS50a and its derivate QT8343) genotypes, becoming maximal at 4 weeks after $P$. thornei inoculation. The activity of POD was induced in CPI133872 at 6 weeks after P. thornei inoculation. Different genetic sources of resistance to $P$. thornei showed diverse defense mechanisms and differences in timing responses. The combined effects of total phenols and oxidative enzymes could be important for defense against $P$. thornei in some resistant wheat genotypes.
\end{abstract}

Keywords: Pratylenchus thornei; wheat; resistance; defense response; plant phenols; polyphenol oxidase; peroxidase; microplate reader for enzyme assay

\section{Introduction}

The root-lesion nematode Pratylenchus thornei is a plant-parasitic nematode that causes yield loss in wheat (Triticum aestivum) in many countries [1]. It is one of the major threats to wheat production in the subtropical grain region of eastern Australia [2]. Pratylenchus spp. are migratory endoparasites that secrete cell wall degrading enzymes, such as cellulase, glucanase, and pectate lyase, and, together with stylet thrusting and body movement, they penetrate the epidermis of root cells to feed and migrate within the plant root cortex [3]. The feeding, migration, and multiplication of nematodes damages the root system, resulting in the poor uptake of water and nutrients by the plant, which in turn results in yield loss [4,5]. The life cycle (egg, J2, J3, J4, and adult) of Pratylenchus is completed within 45 to 60 days $[3,6,7]$, resulting in exponential multiplication of the nematode population densities within the growing season of a susceptible wheat crop [8].

The most effective management strategy for $P$. thornei is the use of resistant wheat cultivars $[9,10]$. Resistant host plants retard nematode reproduction in roots, reducing the nematode population densities in the soil to attack subsequent crops [9]. No wheat genotype completely prevents the 
reproduction of $P$. thornei. Hexaploid wheat genotypes $(2 n=6 x=42)$ with high levels of resistance to $P$. thornei have been identified, including GS50a, a selection from the susceptible wheat cultivar, Gatcher [11], West Asian and North African wheat landraces [12], Iranian wheat landraces [13], and synthetic hexaploid wheat genotypes $[10,14,15]$. Furthermore, resistance to $P$. thornei has also been identified in tetraploid ( $2 n=4 x=28$, Triticum turgidium subsp. durum (AABB genomes) and diploid $\left(2 n=2 x=14\right.$, Aegilops tauschii (DD genome) and Triticum urata $\left(\mathrm{A}^{\mathrm{m}} \mathrm{A}^{\mathrm{m}}\right.$ genome) genome donors of hexaploid wheat $[16,17]$. Zwart et al. found that the inheritance of resistance in wheat is additive and polygenic [18]. Several quantitative trait loci (QTL) linked to $P$. thornei resistance have been identified in the aforementioned germplasm $[14,15,19,20]$. However, investigations into the mechanisms of resistance conferred by the quantitative trait loci (QTL) in wheat against $P$. thornei are limited.

The first insights into the biochemical resistance mechanisms in wheat to $P$. thornei suggest that defense responses occur post-penetration of the roots because both resistant and susceptible genotypes were penetrated by approximately similar numbers of nematodes [21]. However, P. thornei reproduction rate was found to be significantly less in moderately resistant genotypes than in susceptible genotypes at 16 weeks post-nematode inoculation (PNI) [8]. Thus, upon successful penetration by P. thornei, resistance mechanisms of the wheat plant come into play preventing the reproduction and/or feeding of the nematodes. Defense mechanisms activated in the plant root system could include changes in cellular morphology [22] or the production of biochemical compounds such as primary and secondary metabolites, pathogenesis-related proteins such as chitinases, $\beta-1,3$ glucanases, peroxidases, and/or lipid transfer proteins [23-25]. These changes in defense can be constitutive, such as pre-existing physical barriers or phytoanticipins, or induced phytoalexins that are activated following nematode penetration. Linsell et al. proposed that the defense in resistant wheat against $P$. thornei is constitutive [21]. However, the constitutively expressed biochemical molecules responsible for the defense were not identified in that study.

Phenols are widespread secondary metabolites in plants that have been identified as important compounds in the defense of plants to pathogens [26,27], including defense against certain root-lesion nematode species, namely P. penetrans, P. coffeae, and P. zeae [28-32]. Phenols are mainly produced through the shikimic acid-phenylpropanoid pathway and range from simple phenols, such as cinnamic acid, to complex phenol polymers such as lignin [33]. Matern and Kneusel proposed that phenol is a rapidly synthesized biomolecule after microbial infection, which can be polymerized by oxidative enzymes into cell walls as lignin [34]. Phenols also help to neutralize reactive oxygen species (ROS) that are produced in plants as an immediate defense against pathogenic attack [35]. The reduction in elevated levels of ROS is important for healthy plant cells after preliminary defense. In addition, the migration of nematodes inside the plant root system can cause root cells to produce free phenols, which react with the plant oxidative enzymes polyphenol oxidase (PPO) and peroxidase (POD) to form toxic quinone [27]. Phenols are also known to be involved in plant pigmentation, growth, signaling molecules, and reproduction $[33,34,36]$.

Increases in phenolic compounds and activity of PPO and POD enzymes have been reported to be both constitutive and induced defense mechanisms in plants against root-lesion nematode infection [35]. Studies on the interaction of banana cultivars with P. coffeae showed higher levels of defensive enzymes PPO and POD in both inoculated and non-inoculated treatments of resistant cultivars in comparison to susceptible cultivars, indicating that these enzymes are part of the constitutive defenses of plants $[30,36,37]$. On the other hand, the amount of the phenolic compound chlorogenic acid and PPO increased significantly in resistant tomato root infected by P. penetrans, indicating an induced defense response [38].

There is a lack of knowledge on the role of phenolic compounds and oxidative enzymes PPO and POD in the defense responses in wheat against $P$. thornei. Understanding the constitutive or induced expression of total phenolic compounds in resistant and susceptible wheat genotypes will provide important insights into a possible resistance mechanism of wheat against $P$. thornei. This study focuses on two genetically different sources of P. thornei resistance, CPI133872 and GS50a [18], and 
susceptible wheat genotypes (Janz and Gatcher), and aims to gain insights into possible resistance mechanisms in wheat against $P$. thornei by investigating constitutive and induced levels of (i) total phenols, (ii) PPO activity, and (iii) POD activity, at different time points after nematode inoculation. The relationship between total phenol levels and resistance level is further explored in a larger number of wheat genotypes, ranging from resistant to very susceptible to $P$. thornei.

\section{Results}

\subsection{Experiment 1: Accumulation of Total Phenols Over Time}

The concentration of total phenols in the roots of both resistant and susceptible genotypes increased over time from 2-8 weeks post-nematode inoculation (PNI), with non-inoculated treatments decreasing at 6 weeks before increasing again by 8 weeks (Figure 1). The resistant genotype CPI133872 had significantly higher $(p<0.05)$ concentrations of total phenols than GS50a and QT8343 (a derivate of GS50a) and susceptible genotypes (Janz and Gatcher) for both inoculated and non-inoculated treatments at all time points. The concentration of total phenols for non-inoculated CPI133872 ranged from $506.3 \mu \mathrm{g}$ gallic acid equivalent (GAE)/g root at 2 weeks to $802.2 \mu \mathrm{g}$ GAE/g root at 8 weeks. Similarly, the concentration of total phenols for inoculated CPI133872 ranged from $493.0 \mu \mathrm{g}$ GAE/g root at 2 weeks to $725.4 \mu \mathrm{g} \mathrm{GAE} / \mathrm{g}$ root at 8 weeks. Contrastingly, all other genotypes ranged from $279.0-403.4 \mu \mathrm{g}$ GAE/g root at 2 weeks to $451.8-628.9 \mu \mathrm{g} \mathrm{GAE} / \mathrm{g}$ root at 8 weeks.

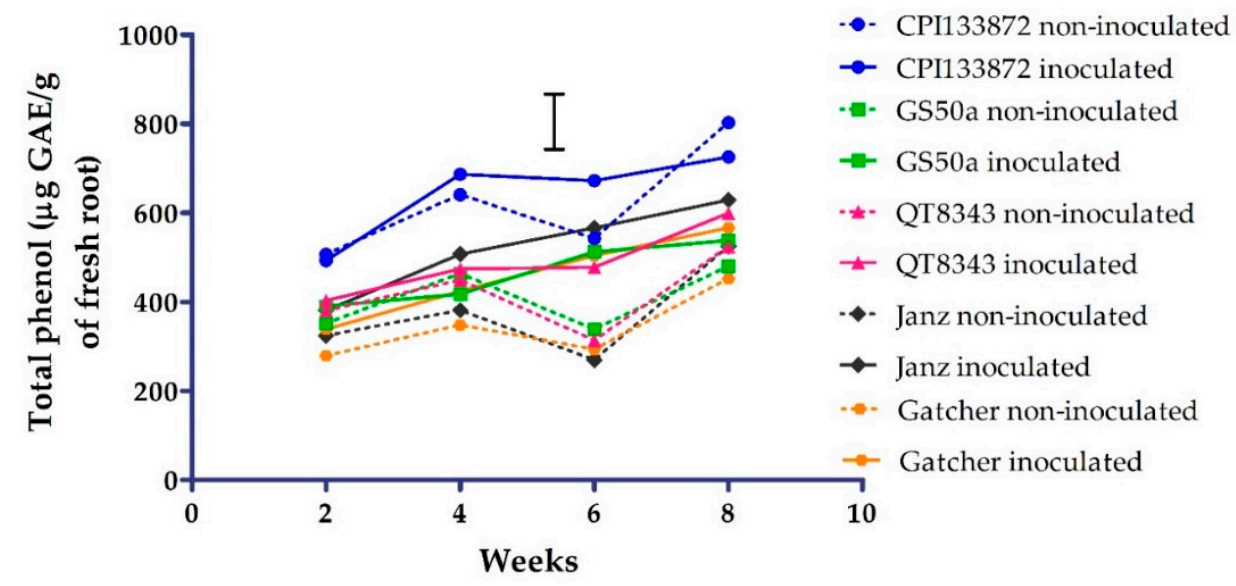

Figure 1. Total phenols ( $\mu$ g gallic acid equivalent (GAE)/g of fresh root) from 2-8 weeks in the roots of Pratylenchus thornei inoculated (solid line) and non-inoculated (dotted line) resistant wheat genotypes-CPI133872 (blue), GS50a (green), and QT8343 (red)—and susceptible wheat genotypes-Janz (black) and Gatcher (orange). The values are the means of three replicates. The bar marker indicates the least significant differences $(\mathrm{LSD})=154(p=0.05)$ for the interaction genotype* P. thornei * time.

\subsection{Experiment 2: Constitutive Levels of Total Phenols in Gnotobiotic Conditions}

The high level of total phenols in non-inoculated resistant genotype CPI133872 was confirmed in an assay conducted under gnotobiotic conditions. Total phenols in non-inoculated treatments for CPI133872 (719 $\mu \mathrm{g}$ GAE/g root) were significantly higher $(p<0.05)$ than all other non-inoculated genotypes, which ranged from $377 \mu \mathrm{g} \mathrm{GAE} / \mathrm{g}$ for susceptible genotype Gatcher to $435 \mu \mathrm{g}$ GAE/g root for moderately resistant genotype QT8343 (Figure 2). 


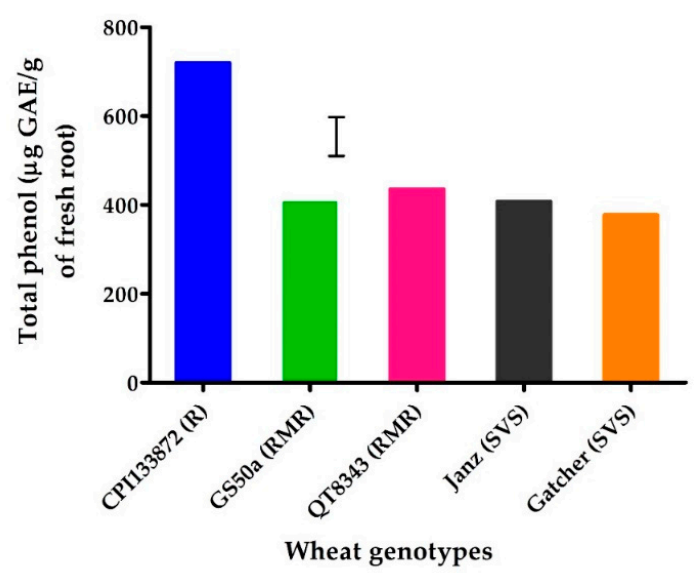

Figure 2. Total phenols ( $\mu$ g gallic acid equivalent (GAE)/g of fresh root) at 3 weeks in the roots of resistant wheat genotypes_CPI133872 (blue), GS50a (green), and QT8343 (red)—and susceptible wheat genotypes-Janz (black) and Gatcher (orange)—grown on agar in gnotobiotic conditions. The values are the means of three replicates. The bar marker indicates LSD $=84(p=0.05)$. The Pratylenchus thornei resistance rating of each wheat genotype is shown in parenthesis $-\mathrm{R}=$ resistant, $\mathrm{MR}=$ moderately resistant, $\mathrm{S}=$ susceptible, and VS = very susceptible.

\subsection{Experiment 3: Total Phenols in Wheat Genotypes Ranging in Resistance/Susceptibility to P. thornei}

The evaluation of the concentration of total phenols in 21 wheat genotypes ranging from resistant to very susceptible at 8 weeks PNI, and including genotypes with several different sources of $P$. thornei resistance, revealed a significantly higher $(p<0.05)$ level of total phenols in the two synthetic hexaploid wheat genotypes, CPI133872 (576 $\mu \mathrm{g} \mathrm{GAE} / \mathrm{g}$ root) and CPI133859 (518 $\mu \mathrm{g}$ GAE/g root), compared to all other wheat genotypes for both inoculated and non-inoculated treatments (Figure 3).

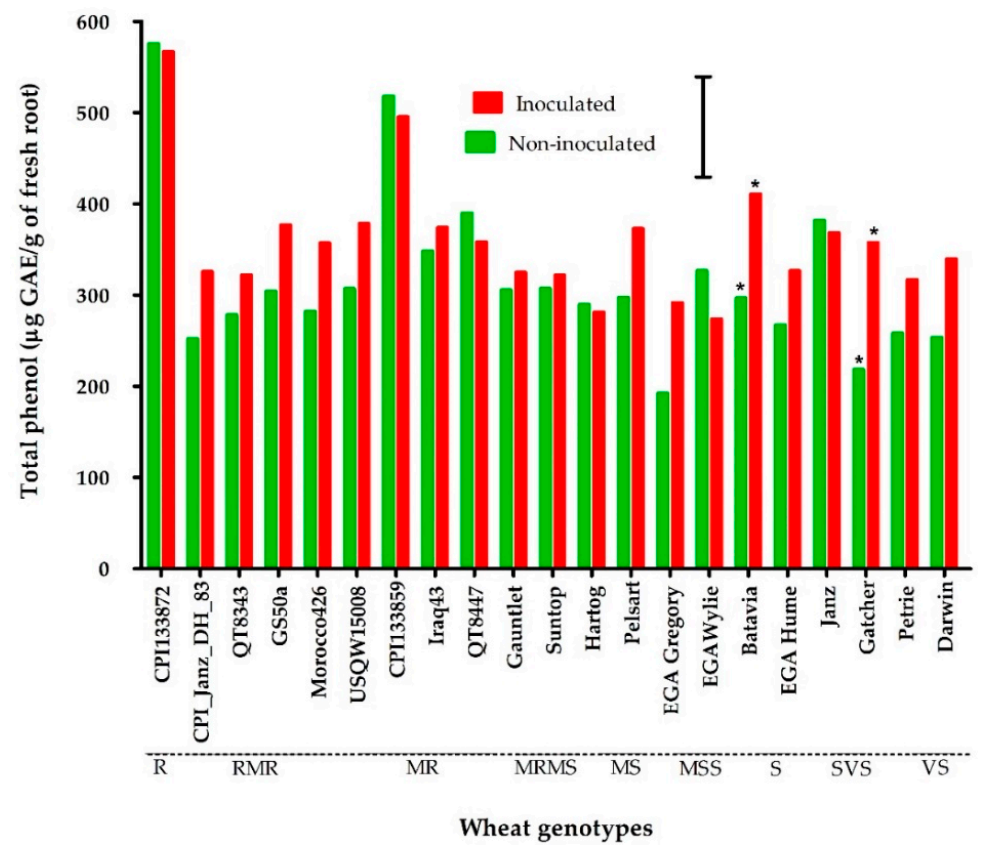

Figure 3. Total phenols ( $\mu$ g gallic acid equivalent (GAE)/g of fresh root) at 8 weeks in the roots of Pratylenchus thornei inoculated (red) and non-inoculated (green) wheat genotypes ranging in resistance and susceptibility to Pratylenchus thornei. The values are the means of three replications. * represent a statistically significant difference $(p<0.05)$ between inoculated and non-inoculated treatments of a genotype. The bar marker indicates LSD $=110(p=0.05)$ for the interaction genotype* $P$. thornei. The resistance rating of each wheat genotype is shown along the $\mathrm{X}$-axis. 
All other non-inoculated treatments of moderately resistant genotypes, namely GS50a and its derivatives QT8343 and QT8447, landraces originating from the Middle East (Morocco426 and Iraq43), and breeding lines derived from CPI133872 (CPI133872_Janz_DH083 and USQW15008) did not accumulate significantly different levels of total phenols (252-390 $\mu \mathrm{g}$ GAE/g root) than the susceptible genotypes (192-382 $\mu \mathrm{g} \mathrm{GAE/g} \mathrm{root).} \mathrm{The} \mathrm{same} \mathrm{trend} \mathrm{was} \mathrm{seen} \mathrm{for} \mathrm{inoculated} \mathrm{treatments,} \mathrm{with} \mathrm{all}$ sources of resistance (other than CPI133872 and CPI133859) not significantly different $(p<0.05)$ in the level of total phenols than the susceptible genotypes, with levels of total phenols ranging from 274-411 $\mu \mathrm{g} \mathrm{GAE/g} \mathrm{root} \mathrm{(Figure} \mathrm{3).} \mathrm{In} \mathrm{general,} \mathrm{the} \mathrm{concentration} \mathrm{of} \mathrm{total} \mathrm{phenols} \mathrm{for} \mathrm{each} \mathrm{genotype} \mathrm{did}$ not differ significantly between inoculated and non-inoculated treatments, except for two susceptible genotypes, Gatcher and Batavia, where the inoculated treatment was significantly higher $(p<0.05)$ in total phenols than the non-inoculated treatment: Gatcher $(219 \mu \mathrm{g} \mathrm{GAE} / \mathrm{g}$ root for non-inoculated and $358 \mu \mathrm{g} \mathrm{GAE} / \mathrm{g}$ root for inoculated) and Batavia ( $297 \mu \mathrm{g}$ GAE/g root for non-inoculated and $411 \mu \mathrm{g}$ $\mathrm{GAE} / \mathrm{g}$ root for inoculated).

\subsection{Polyphenol Oxidase Enzyme Activity}

Polyphenol oxidase enzyme activity in the roots of resistant and susceptible wheat genotypes varied significantly $(p<0.05)$ over time from $2-8$ weeks PNI. At 2 weeks PNI, PPO activity was significantly $(p<0.05)$ higher in only the CPI133872 inoculated treatment (108 tyrosinase equivalent (TE)/0.1 g root) compared with the CPI133872 non-inoculated treatment (55 TE/0.1 g root). For all other genotypes at 2 weeks there were no significant differences $(p<0.05)$ between inoculated and non-inoculated treatments. The activity of PPO increased in inoculated and non-inoculated treatments for all genotypes at 4 weeks and then decreased by 6 weeks and continued to decrease further by 8 weeks (Figure 4). At 4 weeks PNI, the inoculated treatments of the resistant genotype CPI133872 and moderately resistant genotypes GS50a and QT8343 were significantly $(p<0.05)$ higher in PPO activity (103-135 TE/0.1 g root) than the non-inoculated treatments of these genotypes (66-94 TE/0.1 g root). Contrastingly, for susceptible genotypes, no significant differences were found between inoculated (69-85 TE/0.1 g root) and non-inoculated treatments (52-70 TE/0.1 g root). For the susceptible genotype Janz, there were no significant differences between inoculated and non-inoculated treatments at any time point from 2-8 weeks PNI. For the susceptible genotype, Gatcher, the only significant difference $(p<0.05)$ between treatments was recorded at 6 weeks PNI, between inoculated ( $86 \mathrm{TE} / 0.1 \mathrm{~g}$ root, the highest PPO activity level recorded for this genotype) and non-inoculated treatments (50 TE/ $0.1 \mathrm{~g}$ root) (Figure 4).

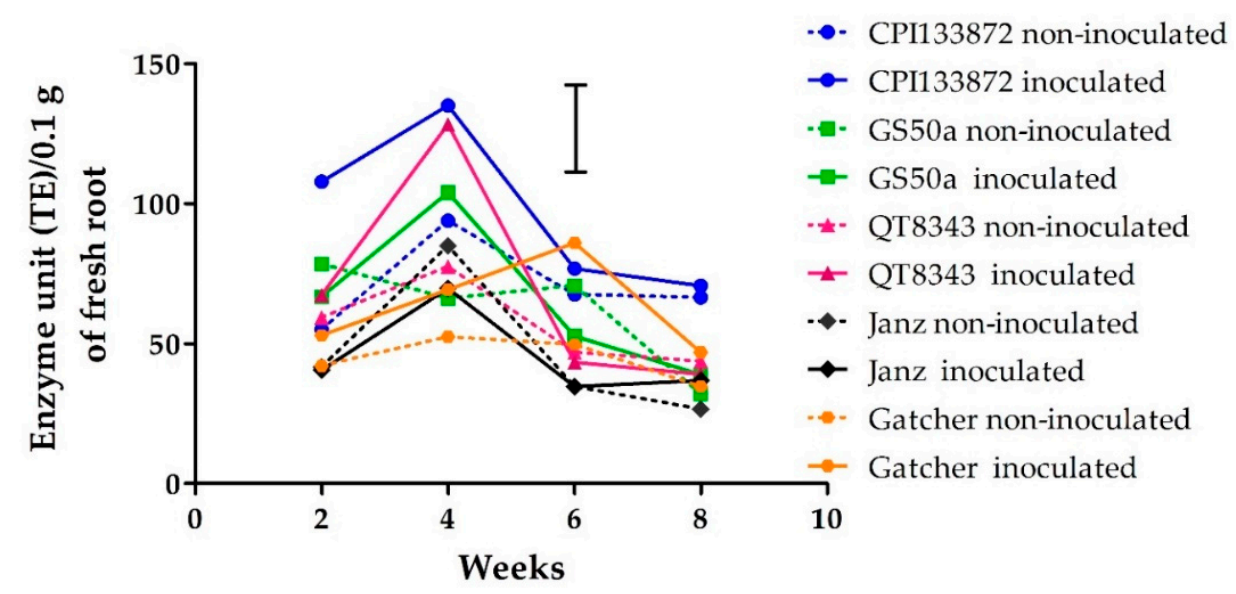

Figure 4. Polyphenol oxidase activity (tyrosinase equivalent (TE)/0.1 g fresh root) from 2-8 weeks in the roots of Pratylenchus thornei inoculated (solid line) and non-inoculated (dotted line) resistant wheat genotypes-CPI133872 (blue), GS50a (green), and QT8343 (red)—and susceptible wheat genotypes-Janz (black) and Gatcher (orange). The values are the means of three replicates. The bar marker indicates LSD $=33(p=0.05)$ for the interaction genotype* $P$. thorne $i^{*}$ time. 


\subsection{Peroxidase Enzyme Activity}

Peroxidase enzyme activity varied significantly $(p<0.05)$ over time between inoculated and non-inoculated treatments for only the resistant genotype CPI133872. The activity of POD increased between 2 and 4 weeks for both inoculated and non-inoculated treatments of all genotypes and then decreased at 6 and 8 weeks, for all genotypes except CPI133872 (Figure 5). The highest levels of POD enzyme activity were recorded at 4 weeks for non-inoculated (59 horse radish peroxidase equivalent (HRPE)/0.1 g root) and inoculated treatments (54 HRPE/0.1 g root) of CPI133872. At 6 weeks, the inoculated treatment of CPI133872 maintained high levels of POD activity (51 HRPE/0.1 g root), whereas the non-inoculated treatment of CPI133872 decreased significantly $(p<0.05)(31 \mathrm{HRPE} / 0.1 \mathrm{~g}$ root) (Figure 5).

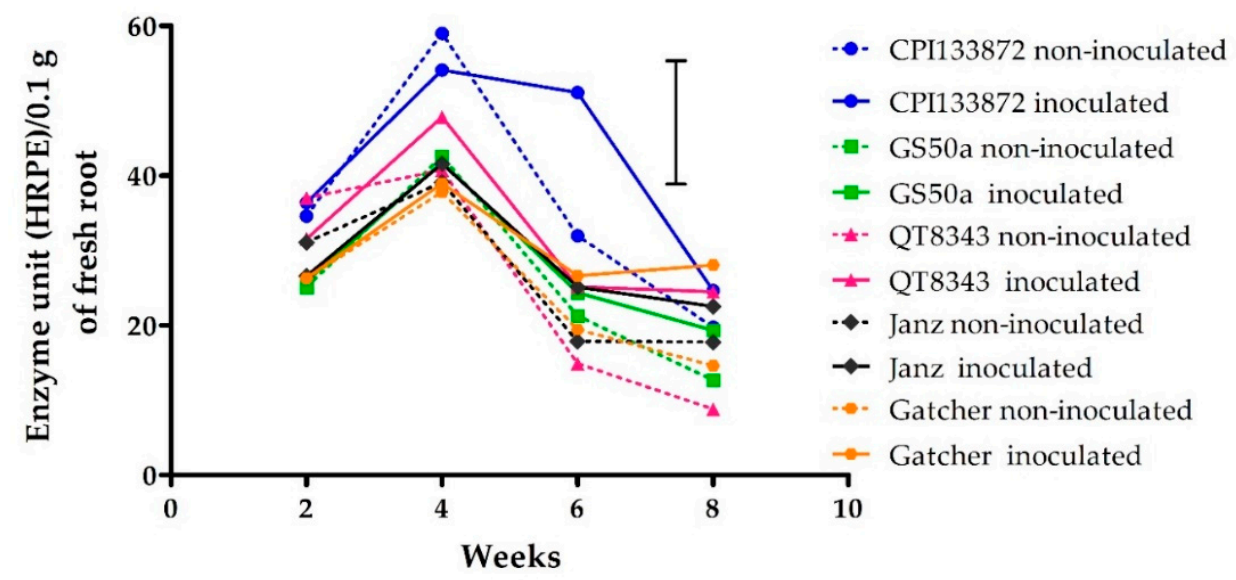

Figure 5. Peroxidase activity (horse radish peroxidase equivalent (HRPE)/0.1 g fresh root) from 2-8 weeks in the roots Pratylenchus thornei of inoculated (solid line) and non-inoculated (dotted line) resistant wheat genotypes-CPI133872 (blue), GS50a (green), and QT8343 (red)—and susceptible wheat genotypes-Janz (black) and Gatcher (orange). The values are the mean of three replicates. The bar marker is $\operatorname{LSD}=17(p=0.05)$ for the interaction genotype ${ }^{*}$. thornei ${ }^{*}$ time.

\subsection{Nematode Quantification}

The presence of $P$. thornei inside the root tissue was confirmed in all inoculated treatments by staining and microscopic observation. Nematodes were also extracted at 10 weeks PNI. The total number of P. thornei/g of dry root were greatest in Gatcher followed by Janz, QT8343, CPI133872, and GS50a. Similar results were obtained for P. thornei $/ \mathrm{kg}$ of soil and roots (Table 1). All nematode life stages (J2, J3, J4 and adults) were observed present in both the stained root samples and the extracts of soil samples of for all genotypes at 10 weeks PNI.

Table 1. Total Pratylenchus thornei numbers (natural log transformed mean value) in different wheat genotypes at 10 weeks post-nematode inoculation.

\begin{tabular}{ccc}
\hline Genotype & $\begin{array}{c}\text { In (P. thornei/g of Dry Root }+\mathbf{1}) \\
\text { (Back Transformed Mean)) }\end{array}$ & $\begin{array}{c}\text { In (P. thornei/kg of Soil and Root + 1) } \\
\text { (Back Transformed Mean) }\end{array}$ \\
\hline CPI133872 & $7.859^{\mathrm{b}}(2588)$ & $8.295^{\mathrm{b}}(4004)$ \\
GS50a & $7.783^{\mathrm{b}}(2399)$ & $8.536^{\mathrm{b}}(5095)$ \\
QT8343 & $8.074^{\mathrm{ab}}(3210)$ & $8.733^{\mathrm{b}}(6204)$ \\
Janz & $8.472^{\mathrm{ab}}(4779)$ & $9.285^{\mathrm{ab}}(10775)$ \\
Gatcher & $8.997^{\mathrm{a}}(8079)$ & $10.018^{\mathrm{a}}(22426)$ \\
\hline
\end{tabular}

Means followed by the same letter in a column are not significantly different by LSD $(p<0.05)$. 
There was no substantial difference in the proportion of life stages among Gatcher, Janz, and QT8343 at 10 weeks PNI. However, some differences in the proportion of life stages per gram of dry root were recorded in Gatcher compared to GS50a and CPI133872 (Figure 6). No contamination of P. thornei in non-inoculated treatments was recorded.

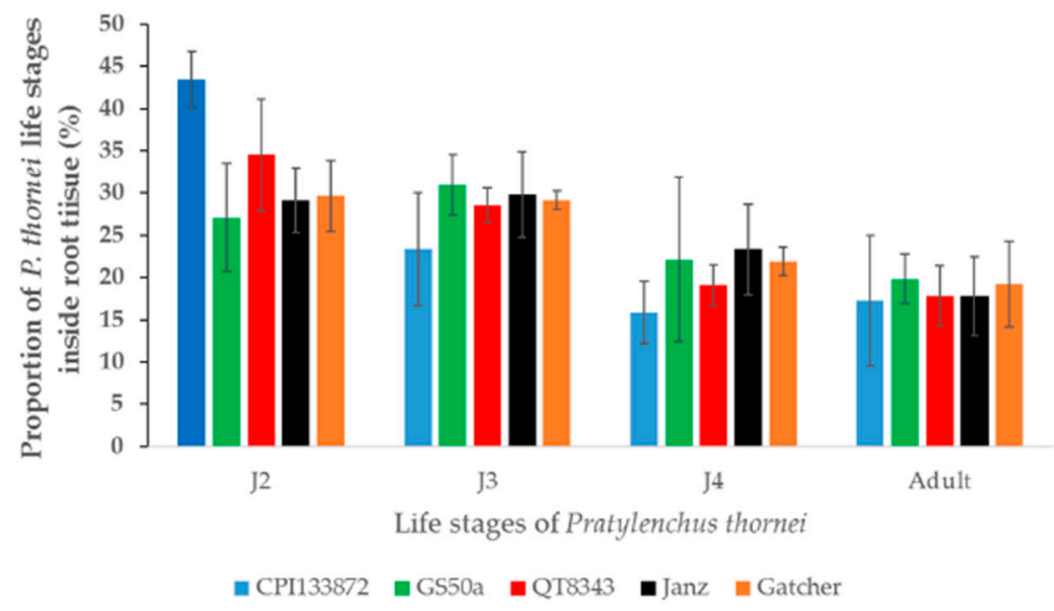

(a)

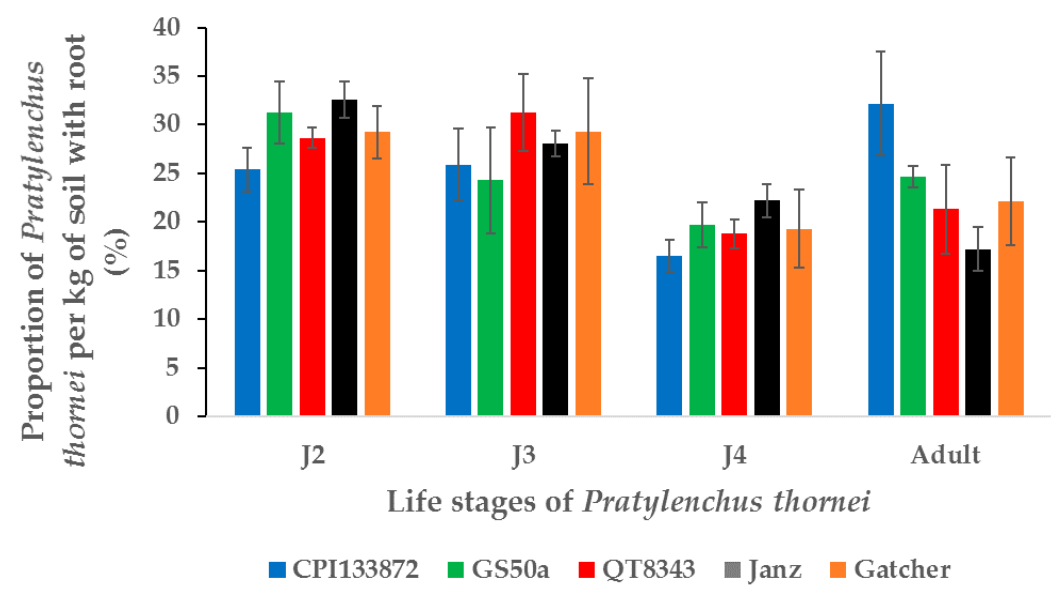

(b)

Figure 6. Proportion of Pratylenchus thornei life stages (a) inside roots of different wheat genotypes and (b) per $\mathrm{kg}$ of soil and root. The values are the mean \pm standard error.

\subsection{Determination of Dry Shoot Weight and Fresh Root Weight}

No significant differences $(p<0.05)$ were observed in the mean dry shoot weights (Figure S1) and fresh root weights (Figure S2) of inoculated and non-inoculated treatments for any of the wheat genotypes.

\section{Discussion}

This is the first study to investigate the defensive role of total phenol content and phenol oxidative enzymes (PPO and POD) in wheat against $P$. thornei. In this study, high constitutive total phenol content in the resistant synthetic hexaploid wheat line CPI133872 was confirmed in three independent experiments. Similarly, high constitutive expression of total phenols was found in another resistant synthetic hexaploid wheat line CPI133859. However, moderately resistant genotypes derived from CPI133872, namely CPI133872_Janz_DH83 (a double haploid line from the cross between CPI133872 and Janz) and its derivative USQW15008 (an advanced breeding line from CPI133872_Janz_DH83) 
did not have higher levels of total phenols than susceptible genotypes at 8 weeks. A similar trend was found in the moderately resistant genotypes GS50a and GS50a-derived lines QT8343 and QT8447, as well as moderately resistant landrace wheats Iraq43 and Morocco426, in which the phenol content was not significantly different from the susceptible genotypes. These results suggest that phenolic compounds may play a role in contributing to $P$. thornei resistance in the synthetic hexaploid lines but not in the other sources of $P$. thornei resistance evaluated in this study.

The synthetic hexaploid wheats CPI133872 and CPI133859 were developed by the International Maize and Wheat Improvement Center (CIMMYT) and share a common durum wheat parent (AABB genome) but different $A$. tauschii parents (DD genome) [10,39]. Studies on the inheritance of P. thornei resistance in these two synthetic hexaploid wheats revealed the minimum number of effective genes to be in the range of four to six genes [39], with CPI133872 and CPI133859 sharing at least one common resistance gene [18]. Resistance in GS50a has been determined to be genetically different from that of CPI133872 and CPI133859 [11,18]. High constitutive total phenol content could be an inheritable component of resistance that was not transferred or alternatively was suppressed when CPI133872 was crossed with Janz.

The significant $(p<0.05)$ decline of total phenols in non-inoculated treatments at 6 weeks in Experiment 1 may be due to the changes in plant developmental stage [40]. During this period, wheat is, generally, at the booting and heading stage depending on the genotype [41]. Iannucci et al. also reported that the concentration of phenolic compounds in the rhizosphere soil of wild oat (Avena fatua) varied with the age of the plant [42]. A sharp decline in phenolic compounds has been reported in that study during stem elongation and early booting stage [42]. However, the total phenol content at 6 weeks PNI in inoculated treatments for both resistant and susceptible genotypes did not decline, contrary to the non-inoculated treatments. This suggests that $P$. thornei infestation might induce changes in phenylpropanoid pathways to keep the phenol production at an increased level irrespective of the changes in the developmental stage of wheat genotypes. Rahman et al. recently identified key enzymes of phenylpropanoids, such as phenyl ammonium lyase and chalcone synthase, as candidate genes in QTL regions on chromosomes 2BS and 6DS for resistance to $P$. thornei in the synthetic derived wheat line Sokoll [43]. Initial QTL mapping studies reported the co-location of resistance to P. thornei in Sokoll on chromosomes 2BS and 6DS with QTL for resistance to P. thornei in CPI133872 [14,19]. However, more recent mapping studies have identified kompetitive allele specific PCR (KASP) markers that select for the CPI133872-derived resistance, but do not select for Sokoll-derived resistance, suggesting that P. thornei resistance in these synthetic hexaploid wheat genotypes is controlled by different genes [44] and therefore with possibly different resistance mechanisms.

Both constitutive and induced phenolic compounds have been previously reported to be responsible for defense in host plants against various root-lesion nematodes [35-38]. Backiyarani et al. reported that total phenol in non-inoculated resistant banana genotypes was higher than in the non-inoculated susceptible genotype, suggesting potential constitutive biochemical defensive against P. coffeae infestation [30]. Constitutive phenols were also responsible for the inhibition of burrowing nematode Radopholus similis infection in banana cultivars [45]. The amount of the phenolic compound chlorogenic acid and PPO increased significantly in the roots of resistant tomato infected by P. penetrans, indicating an induced defense response [46].

Increases in the levels of phenol oxidative enzymes in plants wounded and/or infected by pathogens is well documented. As key enzymes acting on the phenylpropanoid pathway, PPO and POD could play important roles in plant resistance to nematodes in several ways; (a) reaction with plant phenolics to form toxic quinone, (b) the production of reactive oxygen species that can act on pathogens or initiate defensive gene expression, (c) reduction in the availability of cellular protein to plant pathogens, $(\mathrm{d})$ crosslinking phenolic compounds into lignin and other cell wall polymers to strengthen cell walls as a physical barrier to pathogens, and possible formation of brown melanin polymer crosslinking phenols in presence of cellular proteins and amino acids [47-50]. In our study, levels of PPO and POD were higher in CPI133872, GS50a, and QT8343 at 4 weeks PNI than in the 
susceptible genotypes Janz and Gatcher. Combined effects of oxidative enzymes and total phenols at 2 and 4 weeks PNI could be a key factor for defense in P. thornei resistant and moderately resistant wheat genotypes. Higher levels of phenols, PPO and POD, at 2 and 4 weeks PNI could be a factor contributing to the superior resistance of CPI133872 to P. thornei.

Comparative enzyme assays of PPO and POD in the roots of different wheat genotypes were performed using a microplate reader to measure absorbance. Microplate readers have not been commonly used previously for enzyme assays of plant extracts [51]. The concentration of substrates and enzyme extracts was optimized to obtain results in the linear range of enzyme kinetics, and the results were expressed according to standard enzyme activities instead of the international unit (IU) of enzyme activities. A major benefit of using a microplate reader in comparison to cuvette assays is that multiple samples can be analyzed at the same time, which is required for analyzing plant samples with a high number of treatments and biological replicates. Moreover, due to the speed and reproducibility of the procedure, multiple assays can be performed under the same controlled conditions.

Resistance in wheat against $P$. thornei occurs post nematode penetration of the wheat root [21,52]. Significant differences in $P$. thornei numbers between resistant and susceptible wheat genotypes can be reliably found at later times (16 weeks PNI) of plant growth, in which time several life cycles of the nematodes contribute to the exponential increase in nematode numbers [8]. The time points and the tissue location of total phenolic compounds could be very important factors for providing defense against $P$. thornei. Lignin biosynthesis is linked with phenylpropanoid metabolism, which leads to total phenol expression [53]. Higher contents of the oxidative enzymes polyphenol oxidase and peroxidase in moderately resistant genotypes at 2-4 weeks PNI could enhance the polymerization of the phenol monomer monolignol to form lignin [29,54]. The conversion of monolignol into lignin not only can give rigidity to cell walls to retard nematode movement and penetration but it can also protect plant cellulose from nematode degradation [55]. Increases in the total phenols and lignin content of plant cell walls were identified as induced defense responses in resistant banana cultivars on infection by the burrowing nematode Radopholus similis [56]. The estimation of lignin in roots of different wheat genotypes is required to provide insights into the relationship between total phenols and lignin content over time in P. thornei resistant wheat genotypes.

The rapid accumulation of phenolic compounds at the infection sites of plants is a well-documented initial defense response of plants to pathogen infection. Increase in total phenolic compounds at infection sites in susceptible genotypes could be a part of a hypersensitive reaction rather than providing defense in other uninfected parts of the roots. Relatively lower PPO and POD activity in susceptible wheat genotypes might also be responsible for the ineffectiveness of the increased total phenol as a defense mechanism in susceptible genotypes. Hung et al. proposed that oxidized phenol potentially acts against the root-knot and root-lesion nematodes, not the phenol itself [46].

Nematode extraction and root staining confirmed that there was infection in the wheat roots in all inoculated samples. The numbers of $P$. thornei were significantly greater in susceptible genotypes (Gatcher and Janz) than in the resistant (CPI133872) and moderately resistant (GS50a, QT8343) genotypes when extracted at 10 weeks. The compound effect of nematode reproduction at different rates inside different wheat genotypes magnify differences at 16 weeks of plant growth [8]. The P. thornei inoculum used in the experiments contained mixed life stages in approximately equal proportions. Interestingly, soil plus roots from the resistant genotype CPI133872 contained a higher proportion of adult $P$. thornei than soil from other genotypes at 10 weeks PNI. Flavonoids have been shown to reduce the hatching of nematode eggs [57], suggesting that phenolic compounds could affect the proportion of nematode life stages. Furthermore, isoflavonoids are phenolic compounds that have been causally linked to the reduced motility of P. scribneri in resistant lima beans [58] and P. penetrans in lucerne [38]. The resistance of CPI133872 could result in overall fewer numbers of new juveniles, or the juveniles and adults could leave the roots due to unfavorable conditions inside resistant root tissues. Further detailed histopathology observations of the $P$. thornei-wheat interaction over time would be valuable in understanding the effect of host resistance on the nematode life stages. 
Knowledge of the specific types of phenolic compounds and other secondary metabolites in resistant and susceptible genotypes at specific times of $P$. thornei infestation in future studies could further improve our understanding of the defense mechanisms. Moreover, further investigations into larger numbers of wheat lines derived from the synthetic hexaploids CPI133872 and CPI133859 would evaluate the predictive value of total phenol, or specific phenolic compounds, as well as phenol oxidative enzymes, as metabolic biomarkers $[59,60]$ for predicting $P$. thornei resistance phenotypes. A holistic metabolomics approach is recommended for future studies.

\section{Materials and Methods}

\subsection{Plant Material and Growth Conditions}

\subsubsection{Experiment 1: The Accumulation of Total Phenols and Oxidative Enzymes (PPO and POD)} Over Time

Two susceptible wheat genotypes (Gatcher and Janz) and three resistant to moderately resistant wheat genotypes (CPI133872, GS50a, and QT8343) were grown as a glasshouse experiment at the Leslie Research Facility $\left(27^{\circ} 32^{\prime} 02^{\prime \prime}\right.$ S $151^{\circ} 56^{\prime} 09^{\prime \prime}$ E), Toowoomba, Australia, in August to October. Treatments were replicated three times in a factorial randomized block design with five genotypes, two nematode treatments (inoculated and non-inoculated), and five harvest time points $(2,4,6,8$, and 10 weeks post-nematode inoculation (PNI)).

A self-mulching black vertisolic soil was collected from Formartin, Australia $\left(27^{\circ} 22^{\prime} 12^{\prime \prime} \mathrm{S}\right.$ $151^{\circ} 25^{\prime} 53^{\prime \prime} \mathrm{E}$ ), and pasteurized in an air: steam stream at $85^{\circ} \mathrm{C}$ for $45 \mathrm{~min}$ [61]. The soil moisture content was determined by drying $100 \mathrm{~g}$ of steam-pasteurized soil at $105^{\circ} \mathrm{C}$ for $48 \mathrm{~h}$. Slow-release fertilizer Osmocote ${ }^{\circledR}$ Plus Trace Elements (Scott Australia, Baulkham Hills, Australia) was used at the rate of $1 \mathrm{~g}$ per pot of $330 \mathrm{~g}$ soil (oven-dried equivalent). The pots were placed on glasshouse benches fitted with a continuous bottom watering system with water tension maintained at $2 \mathrm{~cm}$ by a capillary system using bidim ${ }^{\circledR}$ matting (Geofabrics Australasia, Brisbane, Australia) [62]. The inoculated treatments were separated from the non-inoculated treatments by a $5-\mathrm{cm}$ gap between the capillary mats to avoid cross-contamination. Under-bench heating was used to maintain soil temperature at $22 \pm 4{ }^{\circ} \mathrm{C}$, the optimum temperature for $P$. thornei reproduction [63]. Soil temperature was monitored throughout the experiment using iButtons (Thermochron ${ }^{\circledR}$, Baulkham Hills, Australia) placed in arbitrarily selected pots at $3 \mathrm{~cm}$ of depth in the soil.

Two seeds were sown on a base layer of soil ( $80 \%$ of the total soil volume). Nematodes were added in a 10-mL liquid suspension to inoculated treatments, at the rate of 3300 P. thornei (J2: $23.5 \%$, J3: $30 \%$, J4: $16.5 \%$ adult $30 \%$ ) equivalent to 10 nematodes/g of oven-dried soil per pot (70 mm square, $150 \mathrm{~mm}$ height). The seed and nematodes were covered with the remaining 20\% soil [62]. Ten days after sowing, plants were thinned to one seedling per pot with a scalpel blade, retaining roots inside the pots. The roots of each genotype were assessed for total phenol content and oxidative enzymes (PPO and POD) at 2, 4, 6, and 8 weeks PNI. A final time-point at 10 weeks was used to assess nematode reproduction in the roots and soil for each genotype.

\subsubsection{Experiment 2: Constitutive Levels of Total Phenols in Wheat Roots under Gnotobiotic Conditions}

Wheat seeds of five genotypes (Gatcher, Janz, GS50a, QT8343 and CPI133872), were grown without P. thornei inoculation in a controlled environment growth cabinet (Bioline, Percival Scientific, IA, USA) for 3 weeks. The seeds were surface sterilized according to $\mathrm{Wu}$ et al. with slight modification [64]. The seeds were covered in $70 \%$ ethanol for $5 \mathrm{~min}$ followed by diluted bleach solution $(\mathrm{NaOCl})(2.5 \%)$ for $15 \mathrm{~min}$. The seeds were then rinsed with sterile Milli- $\mathrm{Q}^{\circledR}$ (Merck, Darmstadt, Germany) reverse osmosis water five times. The seeds were imbibed by soaking in sterile Milli- $\mathrm{Q}^{\circledR}$ water for $12 \mathrm{~h}$, then placed on autoclaved petri plates containing moistened sterile filter paper and allowed to germinate for $48 \mathrm{~h}$. Two-day old surface-sterilized and pre-germinated seedlings were transferred aseptically into Schott bottles (DURAN ${ }^{\circledR}$ GLS 80, DWK Life Sciences, Wertheim, Germany) containing $200 \mathrm{~mL}$ of 
$0.3 \%$ autoclaved tap water agar [64]. Four seedlings were placed on the agar per bottle. The lids were screwed on loosely and then wrapped with parafilm. The experiment was arranged in a completely randomized design with three replicate bottles for each genotype.

Light intensity inside the growth cabinet was maintained at $400 \mu \mathrm{mole} / \mathrm{m}^{2}$ with a photoperiod of $13 \mathrm{~h} \mathrm{light}$ and $11 \mathrm{~h}$ dark. The intensity of the light was measured with a photosynthetically active radiation (PAR) light meter (Li-250A, Li-COR Bio-Sciences, Lincoln, NE, USA). The light wavelength was in the PAR range of 400 to $700 \mathrm{~nm}$. The temperature was maintained at $22 \pm 2{ }^{\circ} \mathrm{C}$ throughout the experiment.

\subsubsection{Experiment 3: Total Phenols in Wheat Genotypes Ranging in Resistance/Susceptibility to P. thornei}

Twenty-one wheat genotypes were selected to cover a range of resistance/susceptibility to P. thornei [65] (Table 2). The wheat genotypes were grown using the same glasshouse conditions as described for Experiment 1. Treatments were replicated three times in a split plot design with plus or minus $P$. thornei inoculation randomized to the main plots and wheat genotypes randomized in the sub-plots in a row : column design. The plants were grown in the glasshouse for 8 weeks from July to September.

Table 2. Origin and resistance rating to Pratylenchus thornei for wheat genotypes.

\begin{tabular}{ccc}
\hline Genotype & Origin & Rating [65] \\
\hline CPI133872 & Synthetic hexaploid & R \\
CPI133872_Janz DH083 & CPI133872 derived line & R-MR \\
QT8343 & GS50a derived line & R-MR \\
GS50a & Selection from Gatcher & R-MR \\
Morocco 426 & Landrace & R-MR \\
USQW15008 & CPI133872_Janz_DH083 derived line & MR \\
CPI133859 & Synthetic hexaploid & MR \\
Iraq 43 & Landrace & MR \\
QT8447 & GS50a derived line & MR \\
Gauntlet & Cultivar & MR-MS \\
Suntop & Cultivar & MR-MS \\
Hartog & Cultivar & MS \\
Pelsart & Cultivar & MS \\
Gregory & Cultivar & MS-S \\
Wylie & Cultivar & MS-S \\
Batavia & Cultivar & S \\
Hume & Cultivar & S \\
Janz & Cultivar & S-VS \\
Gatcher & Cultivar & S-VS \\
Petrie & Cultivar & VS \\
Darwin & Cultivar & VS \\
\hline
\end{tabular}

$\mathrm{R}=$ resistant, $\mathrm{MR}=$ moderately resistant, $\mathrm{MS}$ = moderately susceptible, $\mathrm{S}=$ susceptible, $\mathrm{VS}$ = very susceptible.

\subsection{Sample Collection and Storage}

The plant roots from the pot experiments were washed under running tap water to remove the soil, taking care to minimize damage to the roots. The roots were then washed with sterile Milli- ${ }^{\circledR}$ (Merck, Darmstadt, Germany) reverse osmosis water and then blotted dry with tissue paper. The plant roots from the Schott bottles were removed from the agar and blotted dry gently with tissue paper. The fresh root weight of each plant was recorded. Small pieces $(4$ to $6 \mathrm{~cm})$ of the roots $(300 \mathrm{mg})$ from Experiments 1 and 3 were sampled for acid fuchsin staining, to check nematode infection in the roots of the collected samples. The remaining roots were placed inside $50-\mathrm{mL}$ screwcap falcon tubes and immediately frozen with liquid nitrogen. Frozen roots were stored at $-80{ }^{\circ} \mathrm{C}$ until analyses for total phenols and oxidative enzymes were undertaken. Whole root and soil from the last time point 
(10 weeks) from Experiment 1 was stored at $4{ }^{\circ} \mathrm{C}$ and later used for nematode extraction. The plant tops were oven dried for $48 \mathrm{~h}$ at $80^{\circ} \mathrm{C}$ to determine dry weight.

\subsection{Estimation of Total Phenols}

The total phenol content of the roots was determined by the Folin-Ciocalteu method [66] with slight modifications. A sample of the root material ( $0.1 \mathrm{~g}$ fresh weight) from each treatment, previously ground and homogenized in liquid nitrogen with a chilled mortar and pestle, was transferred to a fresh microcentrifuge tube. Two milliliters of $95 \%$ methanol was added to the finely ground root powder. The root powder in methanol was transferred into a $2 \mathrm{~mL}$ microcentrifuge tube and incubated at room temperature for $48 \mathrm{~h}$. The samples were then centrifuged (Centrifuge $5424 \mathrm{R}$, Eppendorf, Hamburg, Germany) at 13,000 $\mathrm{g}$ for $5 \mathrm{~min}$ and the supernatant containing the root extract was transferred to a fresh microcentrifuge tube. One hundred microliters of root extract was mixed with $200 \mu \mathrm{L}$ of $0.2 \mathrm{~N}$ Folin-Ciocalteu reagents, a mixture of phosphomolybdate and phosphotungstate (Sigma Aldrich, St Louis, MO, USA). Blank tubes were prepared using $100 \mu \mathrm{L}$ of $95 \%$ methanol in place of the root extract. The reaction tubes were thoroughly mixed by vortexing and then incubated for $5 \mathrm{~min}$ at room temperature. Eight hundred microliters of sodium carbonate solution $(700 \mathrm{mM})$ was added to the reaction mixture and further incubated for $2 \mathrm{~h}$ at room temperature in the dark. The tubes were centrifuged at $3000 \mathrm{~g}$ for $30 \mathrm{~s}$ to remove any suspended particles. Two hundred microliters of the supernatant from each sample were transferred to a 96-well microplate (Costar ${ }^{\circledR}$, Thermo Fisher Scientific, Waltham, MA, USA). The absorbance was measured at $765 \mathrm{~nm}$ using a microplate reader (Fluostar Omega, BMG Labtech, Mornington, Australia). The total phenol content was determined by comparison with a standard curve for gallic acid (Sigma Aldrich, St Louis, MO, USA) in the range 0 to $200 \mu \mathrm{g} / \mathrm{mL}$ (Figure S3). The samples were prepared in triplicate and the best-fitted results were used for the calculation of total phenols in the root samples under the same conditions and using the same stock of reagents. Three technical replicates for each of three biological replicates were analyzed and mean values expressed as $\mu \mathrm{g}$ of gallic acid equivalent (GAE)/g of fresh root.

\subsection{Preparation of Enzyme Extracts and Optimization of Protocol for Microplate Reader}

Assays for PPO and POD were performed with root materials collected from Experiment 1. The concentrations of substrates for both PPO and POD were optimized prior to performing the enzyme assays with the wheat root extracts. Enzyme kinetics were tested with commercially purchased tyrosinase (Sigma Aldrich, St Louis, MO, USA, $\geq 1000 \mathrm{unit} / \mathrm{mg}$ of solid) with pyrocatechol as substrate for PPO activity (Figure S4) and horseradish peroxidase (Sigma Aldrich, St Louis, MO, USA, $\geq 250$ unit/mg of solid) with guaicol as substrate in the presence of hydrogen peroxide for POD activity (Figure S5) to prepare standard curves. A regression equation in the linear range from the standard curve was used to calculate enzyme activity in the wheat root tissue samples [67]. Different concentrations of wheat root extracts were tested to find the linear range within the value of standard curve. The amount of PPO in wheat root extracts was expressed as tyrosinse equivalent (TE) $/ 0.1 \mathrm{~g}$ fresh root. The amount of POD was expressed as horseradish peroxidase equivalent (HRPE)/ $0.1 \mathrm{~g}$ fresh root, respectively.

A microplate reader was used to test multiple samples at a time according to Siguemoto and Gut [51] with modification. The protocol was optimized for a microplate reader to calculate PPO activities in multiple wheat samples at a time. Enzymes were extracted from $100 \mathrm{mg}$ of root powder in $0.05 \mathrm{M}$ sodium phosphate buffer $\left(\mathrm{NaH}_{2} \mathrm{PO}_{4}\right.$ and $\left.\mathrm{Na}_{2} \mathrm{HPO}_{4}\right)$ at $\mathrm{pH}$ 7. Root materials were ground in liquid nitrogen with a chilled mortar and pestle. The root powder was homogenized with $2 \mathrm{~mL}$ of phosphate buffer and kept at $4{ }^{\circ} \mathrm{C}$ overnight. The homogenate solution was centrifuged at 15,000 rpm for $15 \mathrm{~min}$ at $4{ }^{\circ} \mathrm{C}$ [68]. The supernatants were transferred to fresh $2 \mathrm{~mL}$ microcentrifuge tubes and kept at $4{ }^{\circ} \mathrm{C}$ until used for the enzyme assay. One hundred microliter of the supernatant was diluted to $1 \mathrm{~mL}$ with phosphate buffer. This supernatant was used as the enzyme extract. Enzyme assays were completed within $2 \mathrm{~h}$ of extraction. A multichannel pipette was used to pipette buffer and enzyme 
extracts followed by the respective substrates of both PPO and POD assays. The assays were done in 96 well microplates $\left(\right.$ Costar $^{\circledR}$, Thermo Fisher Scientific, Waltham, MA, USA).

\subsection{Polyphenol Oxidase Enzyme Assay}

For the PPO enzyme assay, $33 \mu \mathrm{L}$ of the enzyme extract was added to $100 \mu \mathrm{L}$ of sodium phosphate buffer ( $\mathrm{pH} 7$ ). The solution mixture was kept at $25^{\circ} \mathrm{C}$ for $15 \mathrm{~min}$ to equilibrate the temperature. Freshly prepared 0.05 M pyrocatechol (Sigma Aldrich, St Louis, MO, USA) solution was also left to equilibrate at $25{ }^{\circ} \mathrm{C}$ for $15 \mathrm{~min}$. After equilibration, $67 \mu \mathrm{L}$ of pyrocatechol was added to the buffer and the enzyme. The absorbance was taken every $30 \mathrm{~s}$ for $3 \mathrm{~min}$ at $420 \mathrm{~nm}$ wavelength using a microplate reader (Fluostar Omega, BMG Labtech, Mornington, Australia). A blank was set with phosphate buffer and pyrocatechol without the addition of enzymes. The mean enzyme activity for each root sample was calculated from absorbance values at 30 and $60 \mathrm{~s}$ using the regression equations relating enzyme activity to absorbance at those respective times (Figure S4).

\subsection{Peroxidase Enzyme Assay}

The peroxidase enzyme assay was performed with the same enzyme extracts as used for the PPO assay. Forty-two microliters of enzyme extract was added to $125 \mu \mathrm{L}$ of buffer. The solutions were kept at $25^{\circ} \mathrm{C}$ for $15 \mathrm{~min}$ to equilibrate along with freshly prepared $10 \mathrm{mM}$ guiaiacol (Sigma-Aldrich, St Louis, MO, USA) and 6.4 mM hydrogen peroxide (Sigma Aldrich, St Louis, MO, USA). Then, $17 \mu \mathrm{L}$ of equilibrated guaiacol was added to the buffer enzyme mixture followed by $17 \mu \mathrm{L}$ of hydrogen peroxide. The absorbance of the resultant mixture was recorded at $470 \mathrm{~nm}$ every $30 \mathrm{~s}$ for $3 \mathrm{~min}$. The blank was prepared with phosphate buffer and pyrocatechol without the addition of enzymes. The absorbance values at 30 and $60 \mathrm{~s}$ were used for the calculation of enzyme activity as per the regression equation of the standard curve at those respective times (Figure S5).

\subsection{Nematode Quantification}

Pratylenchus thornei were extracted from the roots and soil of the samples collected at the 10-week time point in Experiment 1, using the Whitehead tray method [69]. The roots were separated from soil, washed, and chopped into smaller pieces $(1$ to $3 \mathrm{~cm})$ and placed on a Whitehead tray for extraction at $22{ }^{\circ} \mathrm{C}$. The remainder of the soil samples were put on another Whitehead tray separately to the roots. The root and soil samples were incubated at $22{ }^{\circ} \mathrm{C}$ with $1 \mathrm{~L}$ water per tray for $7 \mathrm{~d}$ and $4 \mathrm{~d}$, respectively, to allow the nematodes to migrate from the roots and soil into the water. A $20-\mu \mathrm{m}$ aperture sieve was used to collect the nematodes in $28-\mathrm{mL}$ sample tubes. Following nematode extraction, the root samples were oven dried at $80^{\circ} \mathrm{C}$ for $48 \mathrm{~h}$ and the dry weight of the roots was recorded. The extracted nematodes were counted using a 1-mL Peters nematode counting chamber (Chalex Corporation, Park City, USA) under an Olympus BX53 compound microscope (Olympus, Tokyo, Japan). The nematode numbers were expressed per $\mathrm{g}$ of dry root and per $\mathrm{kg}$ of soil, respectively.

Root samples from Experiments 1 and 2 were stained with $0.1 \%$ acid fuchsin according to a method modified from Bybd et al. [70]. The roots were chopped and placed inside a stain tube [71] and $10 \mathrm{~mL}$ of acid fuchsin stain $(0.1 \% \mathrm{w} / \mathrm{v}$, prepared in $90 \%$ lactic acid solution) were added to each tube. The roots in acid fuchsin solution were heated in a boiling water bath for 2 min, washed in tap water, and then transferred to a sample tube containing $90 \%$ lactic acid solution. Three drops of $8 \mathrm{~N} \mathrm{HCl}$ were added per tube to aid destaining of the root tissues. The stained nematodes in the roots were observed under an Olympus BX53 compound microscope (Olympus, Tokyo, Japan) in both bright field and differential interference contrast (DIC) modes.

\subsection{Statistical Analysis}

Experimental designs and data analysis were performed using R-software version 3.5.1 [72] and Genstat $^{\circledR}$ for Windows ${ }^{\mathrm{TM}}$ [73]. Analysis of variance (ANOVA) was conducted for total phenol content, PPO activity, and POD activity. The significance of the differences in total phenols, PPO activity, and 
POD activity was tested among genotypes and the inoculation treatments at a $5 \%$ significance level using the least significant differences (LSD).

\section{Conclusions}

Our study has revealed high constitutive levels of total phenols in the synthetic hexaploids CPI133872 and CPI133859. The activity of PPO was induced in resistant (CPI133872) and moderately resistant (GS50a and derivate QT8343) genotypes and was maximal at 4 weeks after $P$. thornei inoculation. The activity of POD was induced in CPI133872 at 6 weeks after $P$. thornei inoculation. Different genetic sources of resistance to $P$. thornei showed diverse defense mechanisms and differences in the timing of responses. The combined effects of total phenols and oxidative enzymes could be important for defense against $P$. thornei in some resistant wheat genotypes.

Supplementary Materials: The following are available online at http://www.mdpi.com/2223-7747/9/4/485/s1, Figure S1: Dry shoot weight (g) of Pratylenchus thornei inoculated and non-inoculated treatments of five wheat cultivars over the time points (2-10 weeks) Figure S2. Fresh root weight of inoculated and non-inoculated treatment of five wheat genotypes over the time points (2-8 weeks). Figure S3. Standard curve of gallic acid for total phenols estimation in wheat root samples. Figure S4 and Figure S5: Standard curves of tyrosinase and horseradish peroxidase in linear range of concentration at different time (30-180 s) of enzyme assay progression.

Author Contributions: Conceptualization, J.P.T. and M.M.R.; Methodology, M.M.R. and J.P.T.; Investigation, M.M.R.; Formal analysis, M.M.R., R.S.Z. and J.P.T.; Visualization, M.M.R.; Supervision, R.S.Z. and J.P.T.; Writing —original draft preparation, M.M.R.; Writing—review and editing, R.S.Z. and J.P.T. All authors have read and agreed to the published version of the manuscript.

Funding: This work is supported by a postgraduate research fellowship for M.R. from University of Southern Queensland.

Acknowledgments: We would like to thank biometricians Bethany Macdonald and Clayton Forknall at Queensland Department of Agriculture and Fisheries, Toowoomba and Rachel King at University of Southern Queensland for their support in experimental design and data analysis.

Conflicts of Interest: The authors declare no conflict of interest

\section{References}

1. Smiley, R.W.; Nicol, J.M. Nematodes which challenge global wheat production. In Wheat Science and Trade; Carver, B.F., Ed.; Wiley-Blackwell: Hoboken, NJ, USA, 2009; Volume 10, pp. 171-187.

2. Thompson, J.P.; Clewett, T.G.; Sheedy, J.G.; Reen, R.A.; O'Reilly, M.M.; Bell, K.L. Occurrence of root-lesion nematodes (Pratylenchus thornei and P. neglectus) and stunt nematode (Merlinius brevidens) in the northern grain region of Australia. Australas. Plant Path. 2010, 39, 254-264. [CrossRef]

3. Fosu-Nyarko, J.; Jones, M.G.K. Advances in understanding the molecular mechanisms of root lesion nematode host interactions. Annu. Rev. Phytopathol. 2016, 54, 253-278. [CrossRef] [PubMed]

4. Thompson, J.P.; Mackenzie, J.; Sheedy, G.H. Root-lesion nematode (Pratylenchus thornei) reduces nutrient response, biomass and yield of wheat in sorghum-fallow-wheat cropping systems in a subtropical environment. Field Crops Res. 2012, 137, 126-140. [CrossRef]

5. Whish, J.P.M.; Thompson, J.P.; Clewett, T.G.; Lawrence, J.L.; Wood, J. Pratylenchus thornei populations reduce water uptake in intolerant wheat cultivars. Field Crops Res. 2014, 161, 1-10. [CrossRef]

6. Baxter, R.I.; Blake, C.D. Pratylenchus thornei-a cause of root necrosis in wheat. Nematologica 1968, 14, 351-361.

7. Vanstone, V.; Hollaway, G.; Stirling, G. Managing nematode pests in the southern and western regions of the Australian cereal industry: Continuing progress in a challenging environment. Australas. Plant. Path. 2008, 37, 220-234. [CrossRef]

8. Thompson, J.P.; Clewett, T.G.; O'Reilly, M.M. Optimising initial population density, growth time and nitrogen nutrition for assessing resistance of wheat cultivars to root-lesion nematode (Pratylenchus thornei). Australas. Plant. Path. 2015, 44, 133-147. [CrossRef]

9. Trudgill, D.L. Resistance to and tolerance of plant parasitic nematodes in plants. Annu. Rev. Phytopathol. 1991, 29, 167-192. [CrossRef] 
10. Thompson, J.P. Resistance to root-lesion nematodes (Pratylenchus thornei and P. neglectus) in synthetic hexaploid wheats and their durum and Aegilops tauschii parents. Aust. J. Agric. Res. 2008, 59, 432-446. [CrossRef]

11. Thompson, J.P.; Brennan, P.S.; Clewett, T.G.; Sheedy, J.G.; Seymour, N.P. Progress in breeding wheat for tolerance and resistance to root-lesion nematode (Pratylenchus thornei). Australas. Plant. Path. 1999, 28, 45-52. [CrossRef]

12. Thompson, J.P.; O'Reilly, M.M.; Clewett, T.G. Resistance to the root-lesion nematode Pratylenchus thornei in wheat landraces and cultivars from the West Asia and North Africa (WANA) region. Crop Pasture Sci. 2009, 60, 1209-1217. [CrossRef]

13. Sheedy, J.G.; Thompson, J.P. Resistance to the root-lesion nematode Pratylenchus thornei of Iranian landrace wheat. Australas. Plant. Path. 2009, 38, 478-489. [CrossRef]

14. Linsell, K.J.; Rahman, M.S.; Taylor, J.D.; Davey, R.S.; Gogel, B.J.; Wallwork, H.; Forrest, K.L.; Hayden, M.J.; Taylor, S.P.; Oldach, K.H. QTL for resistance to root lesion nematode (Pratylenchus thornei) from a synthetic hexaploid wheat source. Theor. Appl. Genet. 2014, 127, 1409-1421. [CrossRef] [PubMed]

15. Zwart, R.S.; Thompson, J.P.; Sheedy, J.G.; Nelson, J.C. Mapping quantitative trait loci for resistance to Pratylenchus thornei from synthetic hexaploid wheat in the International Triticeae Mapping Initiative (ITMI) population. Austral. J. Agric. Res. 2006, 57, 525-530. [CrossRef]

16. Thompson, J.P.; Haak, M.I. Resistance to root-lesion nematode (Pratylenchus thornei) in Aegilops tauschii Coss. the D-genome donor to wheat. Aust. J. Agric. Res. 1997, 48, 553-559. [CrossRef]

17. Sheedy, J.G.; Thompson, J.P.; Kelly, A. Diploid and tetraploid progenitors of wheat are valuable sources of resistance to the root-lesion nematode Pratylenchus thornei. Euphytica 2012, 186, 377-391. [CrossRef]

18. Zwart, R.S.; Thompson, J.P.; Godwin, I.D. Genetic analysis of resistance to root-lesion nematode (Pratylenchus thornei) in wheat. Plant Breed. 2004, 123, 209-212. [CrossRef]

19. Zwart, R.S.; Thompson, J.P.; Milgate, A.W.; Bansal, U.K.; Williamson, P.M.; Raman, H.; Bariana, H.S. QTL mapping of multiple foliar disease and root-lesion nematode resistances in wheat. Mol. Breed. 2010, 26, 107-124. [CrossRef]

20. Schmidt, A.; McIntyre, C.; Thompson, J.; Seymour, N.; Liu, C. Quantitative trait loci for root lesion nematode (Pratylenchus thornei) resistance in Middle-Eastern landraces and their potential for introgression into Australian bread wheat. Austral. J. Agric. Res. 2005, 56, 1059-1068. [CrossRef]

21. Linsell, K.J.; Riley, I.T.; Davies, K.A.; Oldach, K.H. Characterization of resistance to Pratylenchus thornei (Nematoda) in wheat (Triticum aestivum): Attraction, penetration, motility, and reproduction. Phytopathology 2014, 104, 174-187. [CrossRef]

22. Freeman, B.C.; Beattie, G.A. An overview of plant defenses against pathogens and herbivores. Plant Health Instr. 2008, 1-12. [CrossRef]

23. Veech, J.A. Phytoalexins and their role in the resistance of plants to nematodes. Nematology 1982, 14, 2-9.

24. Dixon, R.A. Natural products and plant disease resistance. Nature 2001, 411, 843-847. [CrossRef] [PubMed]

25. Sinha, M.; Singh, R.P.; Kushwaha, G.S.; Iqbal, N.; Singh, A.; Kaushik, S.; Kaur, P.; Sharma, S.; Singh, T.P. Current overview of allergens of plant pathogenesis related protein families. Sci. World J. 2014, $2014,158$. [CrossRef]

26. Farkas, G.L.; Kiraaly, Z. Role of phenolic compounds in the physiology of plant diseases and disease resistance. J. Phytopathol. 1962, 44, 105-150. [CrossRef]

27. Giebel, J. Mechanism of resistance to plant nematodes. Annu. Rev. Phytopathol. 1982, 20, 257-279. [CrossRef]

28. Townshend, J.L. The pathogenicity of Pratylenchus penetrans to strawberry. Can. J. Plant Sci. 1963, 43, 75-78. [CrossRef]

29. Acedo, J.R.; Rohde, R.A. Histochemical root pathology of Brassica oleracea capitata L. infected by Pratylenchus penetrans (Cobb) Filipjev and Schuurmans Stekhoyen (Nematoda: Tylenchidae). J. Nematol. 1971, 3, $62-68$.

30. Backiyarani, S.; Uma, S.; Sundararaju, P.; Mayilvaganan, M.; Saraswathi, M.S.; Arunkumar, G. Time course expression studies during Musa-Pratylenchus coffeae interaction. Indian J. Hortic. 2013, 70, 217-222.

31. Vaganan, M.M.; Ravi, I.; Nandakumar, A.; Sarumathi, S.; Sundararaju, P.; Mustaffa, M. Phenylpropanoid enzymes, phenolic polymers and metabolites as chemical defenses to infection of Pratylenchus coffeae in roots of resistant and susceptible bananas (Musa spp.). Indian J. Exp. Biol. 2014, 52, 252-260.

32. Mehta, U.; Kathiresan, T. Effect of Pratylenchus zeae infection on the expression of isozyme activities in resistant and susceptible sugarcane clones. Nematology 2005, 7, 677-688. [CrossRef] 
33. Kubalt, K. The role of phenolic compounds in plant resistance. Food Sci. Biotechnol. 2016, 97-108.

34. Matern, U.; Kneusel, R.E. Phenolic compounds in plant disease resistance. Phytoparasitica 1988, 16, $153-170$. [CrossRef]

35. Sharma, P.; Jha, A.B.; Dubey, R.S.; Pessarakli, M. Reactive oxygen species, oxidative damage, and antioxidative defense mechanism in plants under stressful conditions. J. Bot. 2012, 2012, 1-26. [CrossRef]

36. Mandal, S.M.; Chakraborty, D.; Dey, S. Phenolic acids act as signaling molecules in plant-microbe symbioses. Plant Signal Behav. 2010, 5, 359-368. [CrossRef] [PubMed]

37. Devi, A.N.; Ponnuswami, V.; Sundararaju, P.; Soorianathasundaram, K.; Sathiamoorthy, S.; Uma, S.; Van Den Bergh, I. Mechanism of resistance in banana cultivars against root-lesion nematode, Pratylenchus coffeae. Indian J. Nematol. 2007, 37, 138-144.

38. Baldridge, G.D.; O'Neill, N.R.; Samac, D.A. Alfalfa (Medicago sativa L.) resistance to the root-lesion nematode, Pratylenchus penetrans: Defence-response gene mRNA and isoflavonoid phytoalexin levels in roots. Plant Mol. Biol. 1998, 38, 999-1010. [CrossRef] [PubMed]

39. Thompson, J.P.; Zwart, R.S.; Butler, D. Inheritance of resistance to root-lesion nematodes (Pratylenchus thornei and P. neglectus) in five doubled-haploid populations of wheat. Euphytica 2012, 188, 209-219. [CrossRef]

40. Saini, R.S.; Arora, Y.K.; Chawla, H.K.L.; Wagle, D.S. Total phenols and sugar content in wheat cultivars resistant and susceptible to Ustilago nuda (Jens.) Rostrup. Biochem. Physiol. Pflanz. 1988, 183, 89-93. [CrossRef]

41. Zadoks, J.C.; Chang, T.T.; Konzak, C.F. A decimal code for the growth stages of cereals. Weed Res. 1974, 14, 415-421. [CrossRef]

42. Iannucci, A.; Fragasso, M.; Platani, C.; Papa, R. Plant growth and phenol compounds in the rhizosphere soil of wild oat (Avena fatua L.). Front. Plant Sci. 2013, 509, 1-7.

43. Rahman, M.S.; Linsell, K.J.; Taylor, J.D.; Hayden, M.J.; Collins, N.C.; Oldach, K.H. Fine mapping of root lesion nematode (Pratylenchus thornei) resistance loci on chromosomes 6D and 2B of wheat. Theor. Appl. Genet. 2020, 133, 635-652. [CrossRef] [PubMed]

44. Mather, D.; (University of Adelaide). Personal communication, 2017.

45. Valette, C.; Andary, C.; Geiger, J.P.; Sarah, J.L.; Nicole, M. Histochemical and cytochemical investigations of phenols in roots of banana infected by the burrowing nematode Radopholus similis. Phytopathology 1998, 88, 1141-1148. [CrossRef] [PubMed]

46. Hung, C.; Rohde, R.A. Phenol accumulation related to resistance in tomato to infection by root-knot and lesion nematodes. J. Nematol. 1973, 5, 253-258.

47. Taranto, F.; Pasqualone, A.; Mangini, G.; Tripodi, P.; Miazzi, M.M.; Pavan, S.; Montemurro, C. Polyphenol oxidases in crops: Biochemical, physiological and genetic aspects. Int. J. Mol. Sci. 2017, 18, 377. [CrossRef]

48. Constabel, C.P.; Barbehenn, R. Defensive roles of polyphenol oxidase in plants. In Induced, Plant Resistance to Herbivory; Springer: Berlin, Germany, 2008; pp. 253-270.

49. Pandey, V.; Awasthi, M.; Singh, S.; Tiwari, S.; Dwivedi, U. A comprehensive review on function and application of plant peroxidases. Biochem. Anal. Biochem. 2017, 6, 1-16. [CrossRef]

50. Vaughn, K.C.; Duke, S.O. Function of polyphenol oxidase in higher plants. Physiol. Plant. 1984, 60, $106-112$. [CrossRef]

51. Siguemoto, E.S.; Gut, J.A.W. Validation of spectrophotometric microplate methods for polyphenol oxidase and peroxidase activities analysis in fruits and vegetables. Food Sci. Technol. 2017, 37, 148-153. [CrossRef]

52. Talavera, M.; Vanstone, V.A. Monitoring Pratylenchus thornei densities in soil and roots under resistant (Triticum turgidum durum) and susceptible (Triticum aestivum) wheat cultivars. Phytoparasitica 2001, 29, 29-35. [CrossRef]

53. Liu, Q.; Luo, L.; Zheng, L. Lignins: Biosynthesis and biological functions in plants. Int. J. Mol. Sci. 2018, 19, 335. [CrossRef]

54. Melillo, M.; Bleve-Zacheo, T.; Zacheo, G. Role of peroxidase and esterase isoenzymes in pea roots infected with Heterodera goettingiana. Nematol. Mediterr. 1992, 20, 171-179.

55. Miedes, E.; Vanholme, R.; Boerjan, W.; Molina, A. The role of the secondary cell wall in plant resistance to pathogens. Front. Plant Sci. 2014, 5, 358. [CrossRef]

56. Dirk, D.W.; Elsen, A.; Mariama, K.; Dhakshinamoorthy, S. Phenols and lignin are involved in the defence response of banana (Musa) plants to Radopholus similis infection. Nematology 2014, 16, 565-576. 
57. Wuyts, N.; Swennen, R.; De Waele, D. Effects of plant phenylpropanoid pathway products and selected terpenoids and alkaloids on the behaviour of the plant-parasitic nematodes Radopholus similis, Pratylenchs penetrans and Meloidogyne incognita. Nematology 2006, 8, 89-101. [CrossRef]

58. Rich, J.R.; Keen, N.T.; Thomason, I.J. Association of coumestans with the hypersensitivity of lima bean roots to Pratyenchus scriberni. Physiol. Plant Pathol. 1977, 10, 105-116. [CrossRef]

59. Steinfath, M.; Strehmel, N.; Peters, R.; Schauer, N.; Groth, D.; Hummel, J.; Steup, M.; Selbig, J.; Kopka, J.; Geigenberger, P. Discovering plant metabolic biomarkers for phenotype prediction using an untargeted approach. Plant Biotechnol. J. 2010, 8, 900-911. [CrossRef]

60. Fernandez, O.; Urrutia, M.; Bernillon, S.; Giauffret, C.; Tardieu, F.; Le Gouis, J.; Langlade, N.; Charcosset, A.; Moing, A.; Gibon, Y. Fortune telling: Metabolic markers of plant performance. Metabolomics 2016, 12, 158. [CrossRef] [PubMed]

61. Thompson, J.P. Treatments to eliminate root-lesion nematode (Pratylenchus thornei Sher \& Allen) from a vertisol. Nematologica 1990, 36, 123-127.

62. Sheedy, J.G.; McKay, A.C.; Lewis, J.; Vanstone, V.A.; Fletcher, S.; Kelly, A.; Thompson, J.P. Cereal cultivars can be ranked consistently for resistance to root-lesion nematodes (Pratylenchus thornei and P. neglectus) using diverse procedures. Australas. Plant. Path. 2015, 44, 175-182. [CrossRef]

63. Thompson, J.; Clewett, T.; O’Reilly, M. Temperature response of root-lesion nematode (Pratylenchus thornei) reproduction on wheat cultivars has implications for resistance screening and wheat production. Ann. Appl Biol. 2015, 167, 1-10. [CrossRef]

64. Wu, H.; Pratley, J.; Lemerle, D.; Haig, T. Laboratory screening for allelopathic potential of wheat (Triticum aestivum) accessions against annual ryegrass (Lolium rigidum). Aust. J. Agric. Res. 2000, 51, 259-266. [CrossRef]

65. Thompson, J.P.; Sheedy, J.G.; Robinson, N.A. Resistance of wheat genotypes to root-lesion nematode (Pratylenchus thornei) can be used to predict final nematode population densities, crop greenness, and grain yield in the field. Phytopathology 2020, 110, 505-516. [CrossRef] [PubMed]

66. Ainswort, E.A.; Gillespie, K.M. Estimation of total phenolic content and other oxidation substrates in plant tissues using Folin-Ciocalteu reagent. Nat. Protoc. 2007, 2, 875-877. [CrossRef]

67. Bisswanger, H. Enzyme assays. Perspect. Sci. 2014, 1, 41-55. [CrossRef]

68. Kar, M.; Mishra, D. Catalase, peroxidase, and polyphenoloxidase activities during rice leaf senescence. Plant Physiol. 1976, 57, 315-319. [CrossRef] [PubMed]

69. Whitehead, A.G.; Hemming, J.R. A comparison of some quantitative methods of extracting small vermiform nematodes from soil. Ann. Appl. Biol. 1965, 55, 25-38. [CrossRef]

70. Bybd, D., Jr.; Kirkpatrick, T.; Barker, K. An improved technique for clearing and staining plant tissues for detection of nematodes. J. Nematol. 1983, 15, 142.

71. Fiske, M.L.; Thompson, J.P.; Clewett, T.G. Stain tubes-An aid for staining vesicular-arbuscular mycorrhizae. Australas. Plant. Path. 1989, 18, 24-25. [CrossRef]

72. R Core Team. R: A language and Environment for Statistical Computing; R Foundation for Statistical Computing: Vienna, Austria, 2017. Available online: https://www.R-project.org/ (accessed on 19 December 2018).

73. VSN, International. GenStat for Windows, 17th ed.; VSN International: Hemel Hempstead, UK, 2014.

(C) 2020 by the authors. Licensee MDPI, Basel, Switzerland. This article is an open access article distributed under the terms and conditions of the Creative Commons Attribution (CC BY) license (http://creativecommons.org/licenses/by/4.0/). 